\title{
Les noms des mudéjars revisités, à partir de Tolède et de Lisbonne
}

\author{
Los nombres de los mudéjares estudiados de nuevo a partir de los casos de \\ Toledo y Lisboa
}

\author{
Mudejar names revisited based on the cases of Toledo and Lisbon
}

\author{
Jean-Pierre MolÉnAT \\ CNRS-IRHT (Paris) \\ jpmolénat@free.fr
}

\begin{abstract}
RESUMÉ
Le présent article se base sur un décompte aussi complet que possible des noms des musulmans (mudéjars) apparaissant dans la documentation castillane et portugaise de Tolède et Lisbonne, aux XIV et XV ${ }^{e}$ siècles. Il montre, par l'examen des différents éléments constitutifs du nom, tant masculin que féminin, que ni les noms personnels, ni l'indication de la filiation, ne reflètent une acculturation au milieu chrétien (qui existe pourtant néanmoins dans une mesure qu'il faudrait nuancer), mais une fidélité aux fondamentaux islamiques et à la tradition généalogique arabe. Surtout s'agissant des membres de l'élite mudéjare, il est parfois possible, à partir des désignations diverses du même personnage, de reconstituer des noms arabes complets, qui montrent la résistance des intéressés à l'acculturation, la volonté de fidélité aux paramètres arabes classiques, derrière l'apparence de la conformité au modèle chrétien dominant.
\end{abstract}

Mots-clés: mudéjars (musulmans). Tolède. Lisbonne. Ism 'alam. nasab. nisba. kunya. acculturation. résistance.

\section{RESUMEN}

Análisis lo más completo posible de los nombres de mudéjares que aparecen en la documentación castellana y portuguesa de Toledo y Lisboa de los siglos XIV y XV. El examen de los diferentes elementos constitutivos del nombre, tanto masculino como femenino, muestra que ni los nombres propios ni la indicación de filiación reflejan una aculturación al medio cristiano -aunque existió en una medida que es preciso matizar- sino que hubo fidelidad a los fundamentos islámicos y a la tradición genealógica árabe. A veces es posible, sobre todo si se trata de miembros de la élite mudéjar, reconstruir nombres árabes completos, lo que muestra la resistencia de los interesados a la aculturación y la voluntad de fidelidad a los parámetros árabes clásicos, detrás de la apariencia de conformidad al modelo cristiano dominante.

Palabras clave: mudéjares (musulmanes). Toledo. Lisboa. Ism. 'alam. Nasab. Kunya. Aculturación. resistencia.

\begin{abstract}
This article is based on an analysis as complete as possible of the names of Mudejars appearing in fourteenth and fifteenth-century documentation of Toledo and Lisbon in Castilian and Portuguese. The study of different elements constituting male as well as female names indicates that neither the proper names nor the indices of filiation reflect Christian acculturation - even if it did exist to an extent that needs to be qualified - but rather, indicated fidelity to Islamic principles and Arab genealogical traditions. At times, especially when dealing with members of the Mudejar elite, diverse designations of a single individual
\end{abstract}


make it possible to reconstruct complete Arabic names, which reveal resistance to acculturation and loyalty to classical Arab parameters behind an appearance of conformity with the dominant Christian model.

Key words: Mudejars (Muslims). Toledo. Lisbon. Ism. 'alam. Nasab. Kunya. Acculturation. Resistance.

Sommaire-index: 1. Le nom personnel (ism 'alam). 2. Les autres éléments du nom: la filiation (nasab). 3.La kunya. 4. Les nisba/s. 5. Les autres surnoms. 6. Comment interpréter cette onomastique? ${ }^{1}$

La grande thèse récente de Filomena Barros sur les mudéjars du Portugal ${ }^{2}$, venant après son précédent ouvrage consacré à la communauté musulmane de Lisbonne ${ }^{3}$, et de nombreux articles ${ }^{4}$, entre autres richesses, fournit les éléments d'une discussion sur l'interprétation de l'anthroponymie de ces musulmans vivant au milieu, et sous le pouvoir, des chrétiens, et en particulier de leur degré d'acculturation à la société chrétienne environnante et dominante, ce thème de l'anthroponymie ayant été peu traité jusqu'ici, ainsi que le relève Filomena Barros, dans l'historiographie des mudéjars des diverses régions de la péninsule Ibérique ${ }^{5}$. Ces éléments peuvent cependant être comparés à ceux dont l'on dispose pour la Castille, particulièrement à Tolède ${ }^{6}$, et, dans une moindre mesure pour la Couronne d'Aragon, singulièrement dans le royaume de Valence ${ }^{7}$, encore que dans cette dernière région la situation soit bien distincte de celle prévalant en Castille et au Portugal, à la fois par la proportion très supérieure de musulmans soumis au pouvoir chrétien, représentant encore $30 \%$

1 Abréviations utilisées dans les notes: AGS, Archivo General de Simancas (Simancas, prov. Valladolid). AHN, Archivo Histórico Nacional (Madrid). ANTT, Arquivo Nacional da Torre do Tombo (Lisbonne). ASC, archives du monastère de San Clemente (Tolède). ADF, archives des ducs de Frías, maintenant déposées à la section Nobleza de l'AHN, à Tolède. Consultées au début des années 1970 au château de Montemayor (Cordoue), avec les cotes correspondantes. CT, archives de la cathédrale de Tolède, Archivo del Cabildo. OF, archives de la cathédrale de Tolède, dites Obra y Fábrica.

${ }^{2}$ Maria Filomena Lopes de Barros, Tempos e Espaços de Mouros. A minoria muçulmana no Reino Português (Séculos XII a XV), Lisbonne, Fundação Calouste Gulbenkian, 2007, désormais référencé comme: Barros, Tempos e Espaços. Un compte-rendu détaillé de notre est parue dans la revue $\mathrm{Al}$ Qanțara (Madrid, 2010).

${ }^{3}$ Maria Filomena Lopes de Barros, A Comuna muçulmana de Lisboa séc. XIV e XV, Lisbonne, Hugin (Biblioteca de Estudos Árabes 4), 1998, désormais référencé comme: Barros, A Comuna.

${ }^{4}$ Spécialement, pour la question traitée ici, Maria Filomena Lopes de Barros, «The identification of Portuguese Muslims. Problems and methodology», dans Arabic-Islamic Medieval Culture, Manuela Marín (ed. et coord.), Medieval Prosopography 23 (2002), Western Michigan University, p. 203-228, désormais référencé comme: Barros, «The identification», et «Os mudéjares portugueses e a afirmação da identidade nacional: da indivisibilidade ao exotismo», dans The Linguistic Construction of Social and Personal Identity: First International Conference on Sociolinguistics in Portugal, Évora, CIDEHUSUniversidade de Évora, 1996, p. 107-110.

${ }^{5}$ Barros, Tempos e Espaços, p. 251.

${ }^{6}$ Nos travaux sur le sujet, depuis J.-P. Molénat, «Les Musulmans de Tolède aux XIVe et XVe siècles», dans Les Espagnes médiévales. Aspects économiques et sociaux. Mélanges offerts à Jean Gautier-Dalché, Annales de la Faculté des Lettres et Sciences humaines de Nice, 1983, p. 175-190, seront cités dans le cours de cet artcle.

${ }^{7}$ Ana Labarta, La onomástica de los moriscos valencianos, Madrid, CSIC, 1987. Désormais référencé comme: Labarta, La onomástica. 
de la population totale au XVIe s. ${ }^{8}$, et parce qu'à cette époque il s'agit de morisques officiellement convertis au christianisme. Mais le maintien de l'arabe chez les musulmans occultes de Valence fournit des éléments de comparaison avec les mudéjars de Castille et de Portugal des XIVe et XVe siècles.

\section{LE NOM PERSONNEL (ISM 'ALAM)}

Le premier élément à considérer est ce que nous désignerons comme le nom personnel, correspondant au ism 'alam musulman, à peu près toujours présent dans la désignation des mudéjars de Castille ou du Portugal. Afin d'unifier les graphies très variables des noms, et de dépasser les différences phonétiques entre les réalisations castillanes et portugaises, nous mettons entre crochets les formes arabes classiques correspondant à chacun des noms.

La statistique de ces noms personnels a été effectuée par nous pour Tolède ${ }^{9}$ et pour le Portugal par Filomena Barros ${ }^{10}$. En se limitant aux cas de Tolède et de Lisbonne, pour comparer le comparable, les résultats sont équivalents.

À Tolède, sur 244 noms d'hommes entre 1326 et 1500, on trouve

- Mahomad [Muhammad]: 45 occurences, soi $18,5 \%$

- Ali ['Alī]: 38 , soit $15,6 \%$

- Hamete [Ahmad]: 37 , soit $15,2 \%$

- Abrahem [Ibrāhīm]: 35 , soit $14,3 \%$

- Abdalla ['Abd Allāh]: 32, soit 13,1 \%

Ces cinq noms représentent ensemble 187 occurrences, soit 76,6\%.

Viennent loin derrière Yahya [Yahyyā]: 9, soit 3,7\%; Ydam [Ādam], Çaed [Șa'īd], 3, soit 1,23 \%; Eçahaba, Esaduba ['I'sā...], 2, soit 0,82 \%; Abderramen ['Abd alRaḥmān], 2, soit 0,82 \%; Abdelhac ['Abd al-Haqq], 2, soit 0,82 \%; Çali [Șāliḥ], 2, soit 0,82\%; Abdelasis ['Abd al-'Azīz], Farax [Farağ]; Haçan [Hasan]; Hasis ['Azīz]; Lope [Lubb]; Omar ['Umar], chacun 1, soit 0,41\%. Reste un Juan García, sur lequel on reviendra.

À Lisbonne, sur 268 occurrences, on a

- Mafomad, Mafamede [Muhammad]: 72, soit 26,87\%

- $\quad$ Azmed [Ahmad]: 37, soit 13,81\%

- $\quad$ Ali ['Alī]: 33, soit 12,31\%

- $\quad$ Brafome [Ibrāhīm]: 22, soit 8,21\%

- Adela ['Abd Allāh]: 15, soit 5,60\%.

${ }^{8}$ Maria Teresa Ferrer i Mallol, «Les mudéjars de la Couronne d'Aragon», dans Minorités religieuses dans l'Espagne médiévale, Revue du Monde Musulman et de la Méditerranée 63-64 (1992), p. 179-194, synthèse commode d'un sujet pour lequel il existe une bibliographie abondante, y compris du même auteur, le plus souvent en catalan.

${ }^{9}$ J.-P. Molénat, «Mudéjars et mozarabes à Tolède du XIIe au XVe siècle», Minorités religieuses dans l'Espagne médiévale, Revue du Monde Musulman et de la Méditerranée 63-64 (1992), p. 143-153.

${ }^{10}$ Barros, Tempos e Espaços, p. 293. 
Viennent ensuite Jufez [Yūsuf]: 15, soit 5,60 \%; Caçome [Qāsim]: 13, soit 4,85 $\%$; Focem [Husayn]: 10, soit 3,73 \%; Omar ['Umar]: 8, soit 2,99\%; Galibo, Galebo [Ǵālib]: 6, soit 2,24 \%; Çolema [Sulaymān]: 6, soit, 2,24 \%; Çaide [Sa'īd]: 5, soit 1,87 \%; Adalmech, Abalmeque ... ['Abd al-Malik]: 4, soit 1,49\%; Farras, Fariche ... [Farağ]: 4, soit 1,49\%; Yça, Hiça... ['Īsā]: 3, soit 1,12 \%; Adão, Adam [Ādam]: 2, soit 0,75 \%; Beder, Bederre [Badr]: 2, soit 0,75\%; Mofarriche, Mafarrache [Mufarriğ]: 2, soit $0,75 \%$; Abelaziz ['Abd al-'Azīz], Amer ['Amr], Acem [Hasan] etc. , chacun 1 , soit $0,37 \%{ }^{11}$.

Si l'éventail apparaît un peu plus ouvert à Lisbonne qu'à Tolède, ce sont les mêmes cinq noms qui viennent en tête, avec un total de 179 occurrences, soit $66,79 \%$. Trois d'entre eux sont des références incontestables à l'islam des premiers temps, à son fondateur Muhammad, dont le nom sous ses deux formes, Muḥammad et Aḥmad, représente 33,7\% des noms masculins à Tolède, 40,7 \% à Lisbonne, et à son gendre 'Alī, l'un des califes rašìdūin.

Le nom théophore "Abd Allāh (littéralement "le serviteur de Dieu") a pu certes être porté par des chrétiens en milieu islamique, Allāh étant pour eux également le nom de Dieu, mais on ne peut pas voir dans son adoption par une portion relativement limitée des mudéjars de Tolède et de Lisbonne une acculturation au milieu chrétien, le nom étant trop chargé de résonance islamique pour des musulmans, au contraire des mozarabes pour qui il avait représenté sans doute une forme d'adaptation au milieu musulman, en al-Andalus ${ }^{12}$ ou ailleurs dans la Dār al-Islām.

De même, on ne verra pas dans les noms de formes diverses dérivés de l'arabe Ibrāhīm une adaptation au milieu chrétien, au motif que le biblique Abraham était également vénéré par les juifs et les chrétiens. D’une part, comme tous les noms de personnages reconnus par les trois religions, tel que Joseph (arabe littéral Yūsuf, mudéjar portugais Jufez, mudéjar tolédan Yuçaf, juif portugais Josepe ou Joce ...), Salomon (arabe littéral Suleymān, mudéjar portugais Çoleyma...), et pour les femmes Marie (arabe littéral Maryam, mudéjar portugais Moreima, mudéjar tolédan Meriem ou Marioca...), le nom utilisé pour Ibrāhīm par les mudéjars (de préférence Brafome pour les portugais, Abrahem pour ceux de Tolède) se distingue parfaitement de celui des juifs et l'on ne sache pas qu'il ait été utilisé, ne serait-ce que sous une autre variante, par les chrétiens castillans ou portugais de la fin du Moyen Âge. L'on peut même s'interroger sur le point de savoir s'il existait un sentiment de l'origine commune de ces noms. L'autre motif pour que l'on refuse d'accepter l'idée que «Bra-

${ }^{11}$ Certaines de ces équivalences pouvant être mises en question, pour les noms les moins fréquents.

${ }^{12}$ On note cependant que ce nom avait été relativement rare chez les mozarabes de Tolède des XIIeXIIIe s., en relevant celui de Abū 1-Ḥasan 'Abd Allāh b. 'Abd al-Malik al-Andurğan̄̄, apparemment un réfugié originaire d'Andujar, avec donc kunya, nasab et nisba géographique, en 1185 (Ángel González Palencia, Los Mozárabes de Toledo en el siglos XII y XIII, 4 vol., Madrid, 1926-1930 -dorénavant cité comme MT, suivi du numéro du document-, doc. $n^{\circ} 178$ ). La nisba al-Andurğanī, dérivé d'une des deux formes du nom de la ville d'Andujar en arabe (Andūšar et Andūğar, cf. Gamal Abd al-Karīm, La España musulmana en la obra de Yãqūt (s. XII-XIII). Repertorio enciclopédico de ciudades, castillos y lugares de al-Andalus. Extraído del Mu'ŷam al-buldān (Diccionario de los países), Grenade, 1974, p. 97, et Évariste Lévi-Provençal, La Péninsule Ibérique au Moyen Âge d'après le "Kitāb ar-raw ḍ al-mi 'țār fì habar al-akțār» d'Ibn 'Abd al-Mun 'im al-Himyarī, Leyde, 1938, texte p. 109, trad. p. 134), montre qu'il ne s'agit pas d'un musulman supposé être resté à Tolède, ou converti sur place, mais d'un mozarabe d'Andalousie réfugié là. 
fome» ait représenté une forme d'acculturation au milieu chrétien, c'est qu'Ibrāhīm, ou ses dérivés dialectaux tels que Brahīm, est bien répandu dans tout le monde arabe, médiéval ou contemporain.

Pour les noms de femmes, on a, à Tolède, sur 53 noms

- Fatima [Fāțima], 10 occurrences: $18,87 \%$

- Xamçy [Šamsī] 10 occurrences: $18,87 \%$

- Maryam (sous les formes Mariam, Meriem, Marioca), 7 occurences: 13,20\%

- Habiba [Habība], avec les variantes Habibo [Habīb-hu] et Habiby [Habībī], 6 occurrences: soit $11,32 \%$

- Haxa ['Á'iša]: 5 , soit $9,43 \%$

- Sohora ou Sohra [Zuhra]; 5, soit 9,43\%

- Fotox [Fatūš ?]: 3, soit 5, 66 \%

- Saynaf, Sayna [Zaynab]: 2, soit 3,77\%

- Nuça [?]: 2, soit, 3,77\%

Asmi, Hasona, Roma, chacune 1 occurence, soit 1,89

À Lisbonne, pour 65 noms de femmes, on trouve

- Moreima [Murayma, diminutif arabe de Maryam]: 12 occurences, soit 18,46\%

- Aixa, Axa, Eixa, Eyxe ['A'A'iša]: 9, soit $13,85 \%$

- Maula [Mawlā]: 8, soit 12,31\%

- Fatus, Fotox ... [Fatūš ?]: 7, soit 10,77 \%

- Aziza, Ziza [‘Azīza]: 5, soit 7,69 \%

- Foteima [Fuțayma, diminutif arabe de Fāțima]: 4, soit $6,15 \%$

- Zoaira [Zuhayra, diminutif arabe de Zahrā']: 4, soit 6,15\%

- Fatima [Fātima], 3, soit 4,62 \%

- Maçoda [Mas'ūda], 3, soit 4,62\%

- Alima [Halìma], 2, soit 3,08\%

- $\quad$ Sauce [Sawsan], 2, soit 3,08\%

- Maryame [Maryam], 1, soit 1,54 \%; de même de Zeina [Zaynab] et Muja [Muhğa] $\ldots$

Le tableau est bien plus contrasté que pour les hommes. À côté des noms de l'épouse préférée et de la fille du Prophète, 'A 'iša et Fāṭima (totalisant à elles deux, avec les diminutifs, 28,23 \% à Tolède, 24,62 \% à Lisbonne), on trouve l'énigmatique Fotox $^{13}$. Au cas où il s'agirait d'une variante de Fātịma, cela porterait les totaux mentionnés à 33,89\% à Tolède, 35,39\% à Lisbonne.

Mais il y a aussi des noms arabes sans connotation religieuse. On relève Šams ${ }^{14}$ (Soleil) et Śamsī (mon soleil) ${ }^{15}$, d'un nom réservé aux esclaves en al-Andalus, et Sawsan (lis, ou iris). La présence de ces noms, sans signification religieuse, montre que

${ }^{13}$ Interprété à Valence comme un diminutif de Fāṭima (Labarta, La onomástica, p. 56). D’autres la considère comme turque.

${ }^{14}$ Attesté non à Lisbonne, mais à Évora et Loulé.

${ }^{15}$ Nous interprétons le -ī final comme un possessif, et non comme une simple voyelle d'appui (Labarta, La onomástica, p. 53-54), à cause de l'espagnol «Mío Sol», clairement un calque de l'arabe pour un nom de femme (el sol étant masculin dans les langues romanes, al-šams féminin en arabe). 
si la législation imposait aux mudéjars (probablement aussi au Portugal), des noms différents de ceux des chrétiens, la prépondérance des noms référant aux premiers temps de l'islam n'était pas obligatoire, mais résultait d'un choix des intéressés.

La fréquence de l'emploi des diminutifs à Lisbonne peut être un trait de mentalité portugaise emprunté par les mudéjars, mais on relève cependant qu'ils sont toujours formés sur des noms arabes et conformément aux règles de l'arabe.

De même que pour les dérivés de Ibrāhīm, Yūsuf ou 'Īsā pour les noms masculins, on ne peut pas considérer les variantes de Maryam pour les femmes comme une acculturation, ou une accommodation au milieu chrétien. Maryam, mère de Jésus, a sa place dans le Coran, y compris avec une sourate en son nom, si elle n'y est évidemment pas la mère de Dieu. Comme pour les hommes, on peut douter que le commun des mudéjars ait eu conscience de l'équivalence entre Maryam-Murayma et la Vierge Marie des chrétiens.

\section{LES AUTRES ÉLÉMENTS DU NOM. LA FILIATION (NASAB)}

Il y a un contraste, au moins apparent, entre le nom arabe, dans sa forme complète, avec nom personnel (ism 'alam), surnom honorifique (kunya), filiation (nasab), nom de relation tribal ou géographique (nisba), autre surnom (laqab), et les noms des mudéjars, tels qu'ils apparaissent dans les documents. Pour certains auteurs, et notamment Filomena Barros, les mudéjars ont adopté le modèle chrétien du nom binaire, formé du nom personnel et d'un autre élément, et voient là un exemple de leur acculturation.

Les choses nous paraissent en réalité moins simples. Ainsi la filiation, pour les mudéjars, ne s'exprime pas pour eux au moyen du patronymique castillan ou portugais en -ez ou -es, mais d'une manière plus proche d'un nasab arabe, soit par un composé de Ibn (Aben ou Ben dans le dialecte arabe, donnant des formes telles que Benaziz pour Ibn 'Azizz), soit par hijo de / filho de, soit par la simple juxtaposition de deux prénoms arabes (Azmede Galebo pour Ahmad [ibn] Ġālib au Portugal) ${ }^{16}$. Si la signification de ces formations est la même que celle du patronymique en son origine, elles en sont néanmoins distinctes .

Il est clair qu'à partir de Galib ou Galebo, on aurait pu former un patronymique Gálvez ou Galves. Si tel n'a pas été le cas, c'est que l'anthroponymie mudéjare ne se moulait pas sur le modèle chrétien, et que l'on a cherché à exprimer le nasab de diverses autres façons, des trois manières précédemment énoncées.

Mais le second nom masculin, originellement sans doute, comme vu précédemment, le nom du père simplement juxtaposé au nom personnel, tend à se fixer et à devenir un nom familial: à Tolède, on a, en 1455, Maestre Yuçaf Abdulasis [Yūsuf b. 'Abd al-'Azīz], «moro, alfarero, morador en Toledo», et sa femme doña Marioca, prenant une boutique du Chapitre cathédral, avec la caution de Maestre Hamete,

${ }^{16}$ Deux exemples probants sont fournis: Azmede Galebo, fils de l'alcaide de la comuna de Lisbonne, Galebo, en 1497; Ale Bucar et son frère Azmede Bucar, de Tavira, en 1473, «filhos de Bucar, mouro forro» [soit 'Alī b. Bakr et Aḥmad b. Bakr] (Barros, Tempos e Espaços, p. 265). 
frère de Yuçaf ${ }^{17}$. En 1477, Maestre Yuçaf Abdulasis et Marioca étant décédés, leurs enfants, Abrahen Abdulasis et sa sœur Abiba s'obligent pour cette boutique ${ }^{18}$. «Abdulasis», peut-être le nom du père de Yuçaf et Hamete, est devenu un nom familial à la génération suivante. En 1480, il est question d'une cour de potiers, appartenant précédemment à Maestre Mahomad Abulaziz ${ }^{19}$, le nom ressemblant ici formellement à une kunya [Abū l-'Azīz], mais n'en étant pas une.

\section{LA KUNYA}

La kunya, surnom honorifique, formé de $A b \bar{u}$... (le père de...), pour les hommes, Umm ... (la mère de ...), pour les femmes, est l'élément le plus caractéristique du nom arabe, mais aussi le seul pour lequel on ne puisse trouver de trace fonctionnelle chez les mudéjars, comme d'ailleurs, après eux chez les morisques ${ }^{20}$.

On peut certes trouver des noms qui ressemblent à des kunya/s, ou que l'on a pu interprêter comme telles, aussi bien à Lisbonne qu'à Tolède, dans des cas le plus souvent douteux, étant donné la facilité de confusion entre les dérivés de $A b \bar{u}$ et de Ibn (dialectal Aben). Au Portugal, on a compris comme «Abū Zayd» la forme Azeite, que l'on pourrit aussi entendre comme «Ibn Zayd» $»^{21}$. A Tolède, les scribes chrétiens hésitent entre les formes «Abdulaziz», «Abdelaziz» et «Abulaziz» pour les mêmes mudéjars.

Cependant, les plus anciennes attestations nominales de mouros forros à Lisbonne, peuvent comporter une kunya fonctionnelle. En 1303, «Abelfocem, mouro forro» prend du monastère de $\mathrm{S}$. Vicente de Fora une parcelle pour y faire une maison, dans le faubourg des mouros de Lisbonne ${ }^{22}$. Le nom s'interprétera comme [Abū 1-Husayn], et comme il n'apparait pas un autre nom personnel, cette kunya peut effectivement avoir fonctionné comme un substitut du nom. De même, en 1320, «Abelmeque, mouro forro, tabelião dos mouros do arrabalde de Lisboa», c'est à dire [Abū 1-Malik] ${ }^{23}$, veuf de Fatoz, et Moula sa sœur, vendent une propriété qui appartenait à la défunte, à Benfica, dans les environs de Lisbonne ${ }^{24}$. On pourrait, il est vrai, comprendre également que, dans ces deux cas, la kunya a cessé de fonctionner comme telle et est devenue un nom personnel ${ }^{25}$. Dans les cas où la kunya est apposée, non à un surnom, mais à un nom personnel, on pourrait supposer qu'elle est encore utilisée comme telle,

\footnotetext{
${ }^{17}$ OF $1091, \mathrm{f}^{\circ} 321$.

${ }^{18}$ OF 959, f $^{\circ} 146 \mathrm{v}$.

${ }^{19}$ OF $1287, \mathrm{f}^{\circ} 125 \mathrm{v}^{\circ}$.

${ }^{20}$ On constate le petit nombre de référence à des noms formés avec Abū dans Labarta, La onomástica, p. 76-77.

${ }^{21}$ Barros, Tempos e Espaços, p. 288-289.

22 ANTT, S. Vicente de Fora, mç 8, $\mathrm{n}^{\circ} 28$.

${ }^{23}$ On pourrait, à vrai dire, comprendre aussi «Abelmeque» comme une cacographie pour «Abdelmeque» ['Abd al-Malik], bien plus courant. F. Barros lit «Abalmeque» (Tempos e Espaços, p.
} 687).

${ }^{24}$ ANTT, S. Vicente de Fora, mç 6, n 22.

${ }^{25}$ On cite des cas, dans le monde arabe classique, où la kunya est devenue un ism 'alam (Jacqueline Sublet, Le voile du nom. Essai sur le nom propre arabe, Paris, 1991, p. 54-55). 
ainsi pour «Maffomade Aboxixa» [Muḥammad Abū Šǐša], possédant une maison à Moura en $1340^{26}$, avec qui on serait en présence d'une kunya-surnom («l'homme à la pipe»), n'exprimant pas une relation de filiation ${ }^{27}$.

Le seul exemple indubitable d'emploi d'une kunya dans sa fonction originelle à l'intérieur de l'espace portugais chrétien, est fourni par l'épitaphe d'Abū l-Walīd Ismā'il b. Ab̄̄ 'Abd Allāh al-Anșāīī, décédé le 17 Ša ‘bān 769 H., correspondant au 7 avril 1368 de notre ère ${ }^{28}$, sur laquelle on reviendra plus loin.

\section{LES NISBA/S}

On sait que les «noms de relations» (nisba/s) inclus dans le nom arabe sont de deux sortes: nisba/s tribales rattachant l'intéressé à l'une ou l'autre des tribus arabes, et nisba/s géographiques le mettant en rapport avec une localité, qu'il y soit né, qu'il y ait séjourné, ou seulement passé29.

En ce qui concerne les mudéjars, une nisba tribale signifiera la revendication d'une appartenance, réelle ou fictive, à l'un des groupes issus de la péninsule Arabique. Quant à la nisba géographique, on considérera sa signification comme distincte de celle d'un surnom d'origine, exprimé en castillan ou en portugais par la préposition «de».

À Tolède, la nisba tribale al-Qaysī accompagne le nom de don Mahomad de Toledo dans sa signature arabe: «Muhammad b. Yūsuf al-Qaysī», dans l'un des rares documents conservés de la pratique des alcaldes mayores de los moros de Castille, dans le corps du texte duquel il est désigné seulement comme «don Mahomad, alcalle mayor por nuestro sennor el rey, de todas las aljamas de los sus regnos e sennorios $\rangle^{30}$. D'autres documents permettent de mieux préciser son identité, et de suivre la persistance de la nisba chez ses descendants. «Don Mahomad de Toledo, moro, alcall mayor de las aljamas de los moros de Castilla», apparaît en 1408, au nom de ses enfants, Yuçaf, Hamete, Fatyma et Xançi, nés de sa femme décédée, doña Sohara, fille de don Lope et de doña Fatima, dans la liquidation du procès portant sur la propriété des quatre-vingt quatre boutiques des Alatares de Tolède ${ }^{31}$. En 1458, on parle à Tolède d'une maison appartenant aux héritiers de feu «don Mahomad Alcayçi,

${ }^{26}$ Chancelaria de D. Afonso IV, t. 3, n 263, p. 19. Autres cas, tels celui de «Ale Bofar» ['Alī Abū Faḥr] (Barros, Tempos e Espaços, p. 267).

${ }^{27} \mathrm{~J}$. Sublet, Le voile du nom, p. 46-49.

${ }^{28}$ A. Goulart de Melo Borges, «Epigrafia Árabe no Gharb», dans Portugal Islâmico. Os últimos sinais do Mediterraneo, Lisbonne, 1998, p. 236-252. BARROS, «The identification». Nous ignorons si l'épitaphe d'Abū Bakr Yahyā b. 'Abd Allāh Ibn al-Hawwarī, datée de 598 H/ 1202 est attribuable au territoire alors au pouvoir des chrétiens.

${ }^{29} \mathrm{~J}$. Sublet, Le voile du nom, p. 95 et suivantes.

${ }^{30}$ E. Sáez, Colección diplomática de Sepúlveda 1, Ségovie, 1956, p. 534-538. La signature a été lue par E. García Gómez et est reproduite en fac-similé entre les p. 536 et 537. Le document n'est pas daté, mais doit être attribué à la première moitié du XVe siècle.

${ }^{31}$ CT, E.6.A.2.2. Notice dans Ramón Gonzálvez Ruiz, Hombres y libros de Toledo, Madrid, Fundación Ramón Areces, 1997, p. 61, note 76. Ce document est probablement l'un de ceux utilisés, sans référence, par Narciso de Estenaga, «Condición social de los mudéjares de Toledo durante la Edad Media», Boletín de la Real Academia de Bellas Artes y Ciencias Históricas de Toledo (1924), p. 5-27. 
alcalde mayor que fue de las aljamas de los moros de Castilla» ${ }^{32}$, et l'on mentionne la même année la veuve et les héritiers de «don Yuçaf Alcayçi, espeçiero, moro, fijo del alcalld moro» ${ }^{33}$, ceux-ci étant nommés l'année suivante: doña Xençi, veuve de «don Yuçaf Alcayçi, moro», Hamete Alcayçi, espeçiero, leur fils, et don Yuçaf Xenteyli, veuf de leur fille, doña Sohora, comme administrateur de ses enfants, Mahomad, Hamete et Habibo, tous «moros, moradores en Toledo», vendent une maison ${ }^{34}$. D'autres Alcayçi, marchands d'épices (especieros) ou boutiquiers (tenderos), sont encore mentionnés à Tolède, au milieu, ou dans la seconde moitié du XVe siècle. Bien que probablement proches des précédents, il ne nous a pas été possible d'établir leur rapport exact avec eux, ainsi pour Abrahen Alayçi, «tendero, moro», fils de feu don Yuçaf Alcayçi et de sa femme doña Hebiba, «moros, moradores en Toledo», possédant en 1480 une maison par héritage de son père et donation de sa mère, sur la place du Solar de los Esparragos, jouxant la mosquée (el alma[gid] de los moros desta dicha çibdad) ${ }^{35}$, qui ne peut pas être le fils du Yuçaf Alcayçi, déjà défunt en 1458. On a encore don Abdalla Alcayçi, tenant en 1488-89 une boutique dans 1'Alcanáa ${ }^{36}$. Ainsi la nisba al-Qaysī se maintient-elle à Tolède durant près d'un siècle, quasiment jusqu'à l'abolition du statut des mudéjars, en 1502.

Les $n i s b a / s$ géographiques élucidées sont au nombre de deux à Tolède: el Xarafi et el Rondí. La première, transcrivant al-Šarafĩ, indique une origine dans l'Aljarafe (alŠaraf), la contrée oléicole des environs de Séville. La seconde est à mettre en rapport avec la ville de Ronda, dans la région de Grenade.

S'agissant, pour al-Šaraf, d'une contrée conquise par les chrétiens dès 1248 , et d'un nom, al-Xarafi, largement répandu dans diverses parties de la péninsule Ibérique chrétienne, on peut penser à une immigration résultant d'une captivité à la suite de la conquête, suivie d'une libération, par rachat ou autrement, sans retour vers la région d'origine ${ }^{37}$. Le vide existant entre le milieu du XIIIe siècle, et l'année 1347, où apparaissent à Tolède don Mahomad Xarafí et son fils Hamete ${ }^{38}$, est partiellement comblé par la mention dans la ville en 1282 d'un musulman, 'Alī al-Daqqāq b. 'Abd Allāh, originaire de l'Aljarafe de Séville (min Šarăf [sic] Išbūliya) ${ }^{39}$. Quoi qu'il en soit les Xarafī sont attestés à Tolède du milieu du XIVe siècle à la fin du XVe, fournissant le dernier des alcaldes mayores de los moros de Castille ${ }^{40}$.

${ }^{32}$ AHN, Clero, carp. 2091/5.

${ }^{33}$ AHN, Clero, carp. 3016/16 (Sta María del Carmen).

${ }^{34}$ AHN, Clero, carp. 3091/7 (Santo Domingo el Real de Toledo).

${ }^{35}$ AHN, Clero, carp. 3016/19.

${ }^{36}$ OF $1285, f^{\circ} 149 v^{\circ}$. OF $91, f^{\circ} 204 v^{\circ}$.

${ }^{37}$ On a cité deux cas de savants musulmans de Cordoue, captifs, puis rachetés, qui préfèrèrent rester à Tolède, pour enseigner les musulmans (P. Guichard et J.-P. Molénat, «Dans al-Andalus, les ulémas face aux chrétiens», dans A. Bazzana, N. Bériou et P. Guichard (éds.), Averroès et l'averroïsme. Un itinéraire historique du Haut Atlas à Paris et à Padoue. Actes du colloque international organisé à Lyon, les 4 et 5 octobre 1999, Presses Universitaires de Lyon, 2005, p. 191-200.)

${ }^{38} \mathrm{cf}$. infra.

${ }^{39}$ MT 866.

${ }^{40}$ J.-P. Molénat, «Une famille de l'élite mudéjare de la Couronne de Castille: les Xarafí de Tolède et Alcalá de Henares», dans Mélanges Louis Cardaillac. Études réunies et préfacées par Abdeljelil Temimi, Zaghouan (Tunisie), 1995, t. 2, p. 765-772; «À propos d'Abrahen Xarafí: les alcaldes mayores de los 
Pour el Rondí, on supposera que le premier à porter cette nisba à Tolède, et le premier alcalde mayor de moros attesté en Castille, a dû y venir depuis Ronda vers le milieu du XIVe siècle, peut-être dans un moment d'accord entre Pierre le Cruel et Muhammad V de Grenade, et quand le souverain castillan recherchait un sage musulman susceptible d'exercer la fonction restée virtuelle depuis Alphonse $\mathrm{X}^{41}$. Don Abdalla el Rondi ['Abd Allāh al-Rundī] dut néanmoins exercer la charge au temps d'Enrique II et durant une période relativement brève, entre 1370 et $1379^{42}$. On connaît un fils de don Abdalla el Rondi, avec qui sa nisba se maintient à Tolède jusqu'au début du XVe siècle, par un document qui donne à penser que don Abdalla, outre ses hautes fonctions judiciaires, avait également exercé comme intendant d'un noble de la ville: en 1426, le testament de García Ferńandez de Tordelobos ordonne que l'on fasse rendre compte à don Mahomad el Rondi, fils de don Abdalla, moro, pour lui et pour son père, du temps où ils avaient géré ses biens ${ }^{43}$. Deux autres documents laissent apparaître don Abdalla el Rondi dans le premier quart du siècle ${ }^{44}$. Et l'on perd sa trace ensuite.

En dehors de ces trois nisba/s clairement identifiables (al-Qaysī, al-Šarafī, alRundī), d'autres noms paraissent ressembler à des nisba/s, sans que l'on ait pu encore les expliquer, ainsi Alçadafi, avec Maestre Farax Alçadafi, maçon et plâtrier («moro, gesero, albanni, morador en Toledo»), exempté de certains impôts dès 1435, avec sa femme Fatima, et ses enfants, son frère Hamete étant mentionné en 1442 (sans doute le même «Maestre Hamete Çadafi, vesino de Toledo», cité ailleurs, en 1440) ${ }^{45}$, avec

moros de Castille au temps des Rois Catholiques», dans VII Simposio Internacional de Mudejarismo (Teruel, 19-21 de septiembre de 1996), Teruel, Centro de Estudios Mudéjares, 1999, p. 175-184.

${ }^{41}$ J.-P. Molénat, «Encore sur la rencontre d'Ibn Khaldûn et de Pierre le Cruel à Séville (1363-64)», dans Mohammed Hammam (coord.), Al-Rihla entre l'Orient et l'Occident (al-Rihla bayna al-Šarq wa-l-Garb), Rabat, Université Mohammed V-Faculté des Lettres, 2003, p. 17-22; «Ibn Jaldún ante Pedro I de Castilla. El revés de un encuentro», dans M. J. Viguera Molins (coord.), Ibn Jaldún. El Mediterráneo en el siglo XIV. Auge y declive de los Imperios. Exposición en el Real Alcázar de Sevilla, Mayo-Septiembre 2006, Séville, El Legado Andalucí, 2006, p. 164-169. Nous avons suggéré que la proposition du souverain castillan à l'historien-philosophe, refusée par celui-ci, de demeurer dans ses états, s'explique par la recherche d'un potentiel alcalde mayor de moros.

${ }^{42}$ Le 3 décembre 1370, Habiby, fille de don Abdalla el Rondi, et veuve de Moheres, «mora, moradora en Toledo», achète la moitié d'une maison, dont le reste appartient à ses enfants, Abdalla et Fatima (AHN, Clero, carp. 3117/5.) Le 30 janvier 1379, la même doña Habibo, fille de don Abdalla el Rondy «alcalde mayor que fue de las aljamas de los reinos de Castilla», (re)mariée à don Hamete, fils de Maestre Çaed el Cong..., approuve la vente faite par le tuteur de ses enfants, Abdalla et Fatima, nés de son défunt mari Mohgrez, de la moitié leur appartenant de la maison. Le tuteur, don Yuçaf, espeçiero, fils de don Abdalla el Zarco, était le frère de Mohgrez [soit l'oncle paternel des mineurs] (AHN, Clero, carp. 3118/16).

${ }^{43}$ AHN, Clero, carp. 2992/16.

${ }^{44}$ Don Mahomad el Rondy et doña Habibo, sa femme, moros moradores en Toledo, le 9 septembre 1416, achètent une pièce de vigne dans les environs de Tolède (AHN, Clero, carp. 2966/13). Maestre Mahomad el Rondi, moro morador en Toledo, le 10 novembre 1419, vend une vigne, probablement la même (AHN, Clero, carp. 2967/4).

${ }^{45}$ AGS, Mercedes y Privilegios, leg. 9, fo 8. 
confirmation par Enrique IV en $1462^{46}$, alcalde mayor de los moros en $1450^{47}$, et quatre ans plus tard également l'un des quatre ou cinq repartidores mayores chargés de partager entre les différentes communautés musulmanes les impôts pesant spécifiquement sur leurs membres ${ }^{48}$.

Une autre nisba non élucidée est Xenteyli ${ }^{49}$, dont les porteurs, à Tolède, dans la seconde moitié du XVe siècle, sont alliés aux Alcayçi, par conséquent appartiennent comme eux à l'élite de la communauté ${ }^{50}$.

En 1347, les deux premiers Xarafí à apparaître semblent porter également une autre nisba, non expliquée, «al-Muhnnafì» (simple conjecture de lecture d'un mot non vocalisé dans leurs signatures arabes) ${ }^{51}$.

Au Portugal, les nisba/s tribales attestées sont au nombre de trois (al-Anșarir ${ }^{-52}$, al-

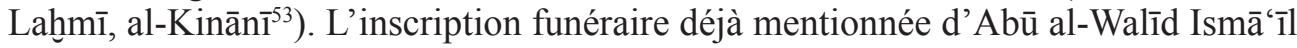
b. Abī 'Abd Allāh al-Anșārī, trouvée à Moura, remonte à la fin du XIVe siècle ${ }^{54}$. La signature arabe de Yūsuf b. Ibrāhīm b. Yūsuf al-Lahmī, également aux dernières années du XIVe siècle ou au début du suivant, double sa signature portugaise «Juf-

${ }^{46}$ AGS, Mercedes y Privilegios, leg. 2, fo 398 vº.

${ }^{47}$ Le 26 juin 1450, Çuleman el Romo, alcalde de l'aljama de los moros d'Avila, «por maestre Farax Alçadafe, alcalde mayor de las aljamas de Castilla» (B. Casado Quintanilla et alii, Catálogo de Protocolos Notariales del Archivo Histórico Provincial de Ávila (siglo XV), Ávila, 1992, t. 1, p. 315, $\left.\mathrm{n}^{\circ} 1118\right)$.

${ }^{48}$ R. Domínguez Casas, Arte y etiqueta de los Reyes Católicos, Madrid, 1993, p. 62, et note 193, p. 177: «Maestre Farax, alcalde», mais aussi les graphies «Alçadichi» et «Alçadifi».

${ }^{49}$ Peut-être en rapport avec šintayla, éclair, étincelle (esp. centella) «encore en usage au Maroc» (Reinhardt Dozy, Supplément aux dictionnaires arabes, 2 vol., Leyde, 1881; réimp., Beyrouth, 1968, t. 1, p. 790a), ou un dérivé du nom de Santaella, localité de l'actuelle province de Cordoue.

${ }^{50}$ En 1459, don Yuçaf Xenteyli, veuf de doña Sohora, fille de don Yuçaf Alcyçi et doña Xençi, agit comme administrateur de ses enfants, Mahomad, Hamete et Habibo (AHN, Clero, carp. 3091/7). Le 2 juin 1486, dans un échange effectué avec la ville, le chapitre cathédral reçoit, deux boutiques situées dans l'Alcaná, tenues par Ali Xenteyle et Mahomad Xenteyle, moros, moradores en Toledo (CT E.7.I.6). Le 23 décembre 1489, Ali Xenteli (ou Xenteyle), moro, especiero, s'oblige envers le chapitre, pour la boutique située dans l'Alcaná «do solia ser tienda del Rey, en la calle de los latoneros», et donne la caution de son frère, Mahomad Xenteyle, et d'Abrahen Alcabçi. Mahomad Xenteyle, moro, s'oblige pour sa boutique et donne la caution d'Ali Xenteyle, son frère, et d'Abrahen Alcabçi (OF 963, $\left.\mathrm{f}^{\circ} 18 \mathrm{v}^{\circ}\right)$.

${ }^{51}$ Peut-être une erreur de lecture pour al-hanafì, soit le hanéfite, ou autre chose. Aucune trace de ce nom n'a été trouveé dans les dictionnaires de noms arabes, tels que le Muštalih d'al Dahabí (ed. Le Caire, 1962).

${ }^{52}$ On assimile à une nisba tribale, le nom anșārī affecté aux gens de Médine ayant aidé Muhammad, les Anșār $r$ comportant en fait deux tribus.

${ }^{53}$ cf. J. Sublet, Le voile du nom, p. 176: «On lit: al-Kinānī, et cela implique que son ancêtre appartenait à la tribu des Banū Kināna ibn Huzayma dont la généalogie était telle et telle, et dont le territoire s'étendait autour de La Mekke de telle à telle région. Et la terminaison ī de Kinānī fait l'économie de la généalogie et de l'énoncé du territoire».

${ }^{54}$ Artur Goulart de Melo Borges, «Panorâmica da epigrafia árabe em Portugal», Estudos Orientais 2 (1991), p. 91-102, spécifiquement p. 99. La datation du XVIe siècle est une coquille évidente, corrigée dans id., «Epigrafia Árabe no Gharb», dans Portugal Islâmico. Os últimos sinais do Mediterraneo, Lisbonne, 1998, p. 236-252. 
fiz». Deux musulmans de Loulé, exerçant des fonctions notariales, sont appelés Alquinene, dans la seconde moitié du XVe siècle ${ }^{55}$.

Les nisba/s géographiques sont plus ambiguës, parce qu'il est souvent impossible de savoir avec certitude à quelle localité elles se réfèrent. Lixbonim [Lišbūnī] exprime évidemment une relation à Lisbonne, pour deux membres de la communauté de Loulé, en Algarve: Ali Lixbonim, confirmé comme notaire (escrivão) de la comuna en 1397, et «Mafomede, neto do Lixbonim», peut-être le petit-fils du précédent à Loulé également en $1424^{56}$. Aragani signifie vraisemblablement un rapport avec l'Aragon. Mais Alcaçari [al-Qașrī] pourrait situer une origine à Alćacer [do Sal], au Portugal, à l'un des al-Qașr du Maroc, notamment al-Qașr al-Șagīir ${ }^{57}$, dans le Nord du pays, où les Portugais s'implantèrent au XVe s., ou à l'un des Alcázar de Castille, dont Alcázar de San Juan est le plus connu, si le contexte où apparaît ce nom ne montrait que le rapport s'établissait avec la place portugaise du Nord marocain. Alcantarim [al-Qanțarī] peut se rapporter à Alcántara en Castille, la Qanțarat al-Sayf d'al-Andalus, limitophe de la frontière portugaise, ou à Alcântara, dans la banlieue de Lisbonne, où se déroula la bataille qui permit, le 25 août 1580, aux forces de Philippe II de s'emparer de la capitale portugaise ${ }^{58}$, lieu au nom attesté dès l'époque médiévale et qui constitue de nos jours un quartier de la ville ${ }^{59}$. On note le diminutif portugais Alcantarinho ${ }^{60}$. La présence ou l'absence de l'article arabe dans le dérivé roman pose problème: on interpréterait vraisemblablement les cas où il est présent comme des noms plus anciennement fossilisés, et ceux où il manque comme plus récents. Mais les exemples tolédans montrent que les occurrences avec ou sans l'article arabe peuvent alterner pour le même nom, avec cependant une tendance à perdre celui-ci avec le temps.

S'il n'est pas possible, du fait sans doute d'un type de documentation différent, de suivre au Portugal comme à Tolède les familles dotées d'une nisba sur plusieurs générations, il est clair qu'il s'agit presque toujours de familles de notables de leurs

${ }^{55}$ Brafome Alquinene [Ibrāhīm al-Kinānī] en 1488, en conflit avec Mafamede Baboso sur les attributions d'escrivão (Barros, A Comuna, p. 136-137). Jufez Alquenine [Yūsuf al-Kinān̄̄], également escrivão à Loulé en 1477 (Barros, Tempos e Espaços, p. 276 et tableau p. 690).

${ }^{56}$ Barros, A Comuna, p. 45; Tempos e Espaços, p. 264. On a peut-être une autre forme de la nisba correspondant à Lisbonne, avec Brafome Lexune [İbrāhīm al-Ušbūn̄̄], musicien (músico), mouro de Lisbonne, recevant, en 1486, une exemption à la requête de la reine Leonor (Barros, $A$ Comuna, $\mathrm{p}$ 113-114, et un autre Brafome Lexune, nattier (esparteiro), prenant en 1478 des biens du monastère d'Alcobaça (Barros, A Comuna, p. 136-137).

${ }^{57}$ En portugais Alcácer Ceguer, prise en 1458 (Voir notamment, dans une bibliographie abondante Luís Filipe F. R. Thomaz, «A evolução da política expansionista portuguessa na primeira metade de quatrocentos», dans De Ceuta a Timor, 2e éd., Lisbonne, 1998, p. 43-147, spécialement p. 138-139).

${ }^{58}$ Rafael Valladares, La conquista de Lisboa. Violencia militar y comunidad política en Portugal, 1578-1583, Madrid, Marcial Pons Historia, 2008, p. $97-99$ (version portugaise: A Conquista de Lisboa, Texto Editores, 2010).

${ }^{59}$ Le 10 mai 1322, le roi D. Dinis baille deux engins pour faire un moulin à marée «hu chamam Alcantara termho de Lixbõa a cabo dessa ponte que hy esta que chamam d'Alcantara» (ANTT, Chancelaria de D. Dinis, Livro 3, $\mathrm{f}^{\circ} 144 \mathrm{v}^{\circ}$ ). Frédéric Vidal, Les habitants d'Alcântara. Histoire sociale d'un quartier de Lisbonne au début du 20e siècle, Villeneuve-d'Ascq, Presses Universitaires du Septentrion, 2006.

${ }^{60}$ Azmede Alcantarinho, reconnu, en 1471, comme l'un des mouros privilégiés de Lisbonne, accepte de contribuer avec la comuna (Barros, A Comuna, p. 121, n. 75). 
communautés, exerçant à Tolède les fonctions de juge suprême des musulmans du royaume (alcalde mayor de las aljamas de los moros de Castilla), et, plus modestement, au Portugal, où n'existe pas l'équivalent de cette charge, celle de notaire (escrivão) de leur communauté, qui, elle, existe à la différence de la Castille. Peu nombreuses au total, elles appartiennent à une élite ${ }^{61}$, ayant eu, peut-on penser, la possibilité de garder le souvenir de leur origine, réelle ou supposée, dans le passé d'al-Andalus ou du Maghreb.

\section{LES AUTRES SURNOMS}

Si on laisse de côté les nisba/s, qui peuvent également être considérées comme des "surnoms", ceux-ci sont de plusieurs types.

On mettra à part les surnoms professionnels, parce qu'une longue pratique des documents montre que, dans la plupart des cas, ils désignent le métier, la profession ou la fonction réellement exercés par l'intéressé, et ne constituent pas une partie intégrante du nom, cette observation étant d'ailleurs également valable pour les noms des chrétiens contemporains et voisins de nos mudéjars.

Il n'est pas douteux que, dans la plupart des cas, au moins à Tolède, le nom de métier qui accompagne le nom d'un musulman désigne bien la profession exercée par celui-ci, et n'est pas encore devenu un nom familial. Le fait est clair lorsque l'acte concerne la location ou la tenue d'un local correspondant à la profession: en 1435, Yuçaf Cayçi, boutiquier musulman (tendero, moro), tient boutique aux environs de la mosquée ${ }^{62}$, et en 1480, son fils Abrahen Alcayçi, également «tendero, moro», reconnaît un cens sur une maison et deux boutiques qu'il possède par héritage dans le parage $^{63}$. De même les marchands d'épices ou de parfums, désignés comme espeçieros tiennent des échoppes dans le marché des Alatares, dont le nom dérive de l'arabe al-'Atțāriñ, avec le même sens ${ }^{64}$.

La chose est particulièrement claire avec les potiers (alfahares, de l'arabe alfahha a r, en espagnol moderne alfareros), prenant des maisons ou des fours dans le faubourg de Tolède appelé el Arrabal, au secteur désigné comme celui des potiers: en 1404 les religieuses de Santo Domingo el Real baillent à cens à «Maestre Abdalla, alfahar», fils de «Hamete el Sarquillo», et à sa femme doña Haxa, «moros mora-

${ }^{61}$ Sur l'existence de ces élites des communautés mudéjares dans les deux royaumes, J.-P. Molénat, outre «Une famille de l'élite mudéjare», déjà cité, «La question de l'élite mudéjare dans la Péninsule Ibérique médiévale», dans F. Themudo Barata (éd.), Elites e Redes Clientelares na Idade Média. Problemas Metodológicos. Actas do colóquio, Lisbonne-Évora, Ed. Colibri-CIDEHUS, 2001, p. 45-53; «L'élite mudéjare de Tolède aux XIVe et XVe siècle. Alfaquís, alcaldes et alcaldes mayores de moros», dans D. Barthélemy et J.-M. Martin (coords.), Liber Largitorius. Études d'histoire médiévales offertes à Pierre Toubert par ses élèves, Paris, Droz, 2003, p. 563-577.

${ }^{62}$ AHN, Clero, carp. 3016/1.

${ }^{63}$ AHN, Clero, carp. 3016/19.

${ }^{64}$ En 1401 et 1408, une boutique du chapitre cathédral «que es en los Alatares» est tenue par «Yahia, espeçiero, moro, sobrino de don Yuçaf Sarco», avec la caution de «Maestre Hamete, moro, tendero» (OF 935, f $31 \mathrm{v}^{\circ}$; OF 936, f $99 \mathrm{v}^{\circ}$ ) 
dores en Toledo», une maison située dans l'Arrabal de Tolède «a los Alfahares» ${ }^{65}$. La même année, Yahya, «alfarero» e Mahomat Zarco «alfarero», «moros moradores en Toledo», prennent pour leur deux vies du chapitre cathédral «el Corral de los alfahares, que dicen el Corral de Santa Maria», situé dans l'Arrabal, avec la caution de Maestre Ysaque «maestro alfarero» ${ }^{66}$, et l'on peut suivre les potiers musulmans dans ce secteur jusqu'aux dernières années du XVe siècle, en notant que si c'est là que se trouvent les fours des potiers, les boutiques de vente de leur production se situent ailleurs, dans le centre de la ville, dans la rue dite «de la Sal», et que les lieux d'habitation sont ailleurs encore, dispersés dans la ville ${ }^{67}$.

Parfois le nom professionnel du fils différent de celui du père fournit l'indication qu'il s'agit bien du métier exercé par l'un et par l'autre: en 1397, «Maestre Hamete, carpintero» est le fils de «Maestre Aly, podador», le charpentier succédant au tailleur de vignes ${ }^{68}$. Lorsqu'au contraire le père et le fils reçoivent le même qualificatif professionnel, la chose est évidemment moins claire: en 1397, «Maestre Aly, albannil», fils de «Maestre Abraen, albannil» n'est que probablement maçon comme son père ${ }^{69}$, et la chose est encore un peu plus douteuse, mais nullement impossible, lorsque ce sont tous les membres masculins de la famille qui sont ainsi désignés de la même façon: en 1396, apparaissent Maestre Ali, carpintero, et ses frères et sœurs, Maestre Mahomad, carpintero, Juan García, carpintero, Fátima, Xamci (femme de Mahomad el Saria) et Hasona (femme de Maestre Abdalla, carpintero), et Fotox, tous fils et filles de Maestre Abdalla, carpintero, et de sa femme doña Mariam, celle-ci décédée, moros demeurant à Tolède («yo Maestro Ali, carpintero, e yo Maestro Mahomad, carpintero, hermano del dicho maestro Aly, e yo Iohn Garçia, carpintero, hermano de los dichos Maestro Ali et Maestro Mahomad, e yo Fatima, hermana de los dichos Maestro Aly e Maestro Mahomad e Iohn Garçia, e yo Xancy hermana de los dichos (...) e muger que so de Mahomad el Sario, con liçençia (...), e yo Hasona, hermana de los dichos (...) e muger que so de Maestro Abdalla, carpintero, con liçençia, e yo Fotox, hermana de los dichos (...), fijos que somos todos de Maestro Hamete, carpintero, e de donna Mariam, quel Criador perdone, moros moradores en Toledo»), à propos de la moitié de maison héritée de leur mère, indivise avec l'autre moitié où réside leur père ${ }^{70}$. Le seul élément un peu énigmatique est le nom de Juan García, que l'on peut tenter d'expliquer de deux façons: soit par la conversion au christianisme de l'intéressé, mais dans ce cas les liens familiaux auraient dû se trouver rompus, soit par la non-observation de la législation obligeant les musulmans à porter des noms différents de ceux des chrétiens, établie depuis Alphonse $\mathrm{XI}^{71}$. Par contre le fait que

${ }^{65}$ AHN, Clero, carp. 3078/12.

${ }^{66}$ OF $1072, \mathrm{f}^{\circ} 21 \mathrm{v}^{\circ}$.

${ }^{67}$ J.-P. Molénat, «Les mudéjars de Tolède: occupations professionnelles et localisation dans l'espace», dans VI Simposio Internacional de Mudejarismo (Teruel, 16-18 septembre 1993), Teruel, Centro de Estudios Mudéjares, 1996, p. 429-435.

${ }^{68}$ ADF, Gálvez y Jumela, sans cote.

${ }^{69}$ AHN, Clero, carp. 3076/13.

${ }^{70}$ ADF, Gálvez y Jumela, sans cote.

${ }^{71}$ M. A. Ladero Quesada, Los mudéjares de Castilla, Grenade, 1989, p. 73, précisant qu'il ne s'agissait que du nom personnel («nombre de pila»), et pas du surnom, ou nom familial («apellido»). 
le mari de Hasona soit également qualifié de carpintero donne à penser qu'il s'agit bien d'un charpentier, comme ses beaux-frères et leur père.

Il en va de même pour les noms de fonctions juridico-religieuses, alcalde (de

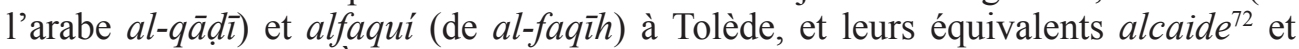
capelão au Portugal. À Tolède, le terme d'alfaquí, comme celui d'alcalde vu précédemment, juxtaposé à un simple nom personnel désigne bien la fonction exercée par le personnage, et n'est pas un nom familial: en 1384, don Yuçaf, especiero, fijo de don Abdalla el Zarco («yo don Yuçaf, espeçiero, ffiio de don Abdalla el Sarco»), et sa femme, doña Xamçí, fille de l'alfaquí don Abrahem Xarafí («e yo su muger, donna Xamçy, ffija de don Abrahem el alfaqui Xarafy», moros demeurant à Tolède («moros moradores en Toledo»), vendent une maison située à Tolède, et en jouxtant une autre ayant appartenu à don Abrahem, alfaquí, père de la vendeuse («que sse tienen con casas que ffueron de don Abrahem alfaqui, padre de mi la dicha donna Xamçy») ${ }^{73}$.

A Lisbonne, «Brafome capellom» apparaît aux dernières années du XIVe siècle ou au début du XVe, en compagnie de Mestre Bucar, Mafomede d'Avis et Farax, tous mouros forros, dans une consultation sur les droits du roi ${ }^{74}$. Il s'agit évidemment des notables de la communauté. Le dernier des "chapelains" de la comuna musulmane lisboète, Azmede Capelão [Aḥmad al-faqīh], vend, après l'édit de décembre 1496 mettant fin à la présence musulmane reconnue comme telle au Portugal ${ }^{75}$, en 1504, par procuration de sa sœur Fatima [Fātima] Capeloa, une boutique de poterie située dans la mouraria, désormais appelée Arrabalde $\mathrm{Novo}^{76}$. Le terme de capelão désigne bien la fonction exercée, et Fatima, sans doute déjà exilée à la différence de son frère, n'est qualifiée de "chapelaine" qu'à cause de celui-ci. «Adeela Almocadem» ['Abd Allāh al-muqaddam] était l'un des deux représentants des mouros de Loulé ayant obtenu une loi de D. Duarte, alors qu'il était seulement infant, héritier présomptif du roi João I, avant $1433^{77}$ : il était effectivement préposé (muqaddam) des musulmans de sa ville.

La réalité de l'exercice du métier désigné par le nom de profession est plus douteuse, lorsqu'il s'agit d'un mot arabe qui n'est jamais passé dans la langue castillane ou portugaise, ainsi Mafamede Almaiar [Muhammad al-Mayyār], nommé en 1397 alcaide $[q \bar{a} d \bar{l}]$ des mouros de Lisbonne ${ }^{78}$, et son presque homonyme Mafamede Almadiar, nommé pour trois ans, en 1475, alcaide de ceux de Tavira ${ }^{79}$, n'exerçaientil probablement pas la profession de muletier, ou de transporteur ${ }^{80}$, s'agissant déjà là d'un nom familial. De même à Tolède, «Farax Jebes, moro morador en Toledo»

${ }^{72}$ Les termes dérivés de deux mots arabes $a l$-qāộ (le juge) et $a l$-qā 'id (le chef militaire), distincts en castillan (alcalde et alcaide) se sont trouvés confondus en portugais, sous la forme alcaide.

${ }^{73}$ AHN, Clero, carp. 3074/2.

${ }^{74}$ Barros, A Comuna, p. 96, et n. 16.

${ }^{75}$ François Soyer, The Persecution of the Jews and Muslims of Portugal. King Manuel and the End of Religious Tolerance (1496-7), Leyde, Brill, 2007.

${ }^{76}$ Barros, A Comuna, p. 247, n. 96; Tempos e Espaços, p. 601.

${ }^{77}$ Ordenanças Afonsinas, Lisbonne, Fundação C. Gulbenkian, 1984, L. 2, Tit. 111, p. 548.

${ }^{78}$ Barros, Tempos e Espaços, p. 683.

${ }^{79}$ Barros, Tempos e Espaços, p. 359, 685.

${ }^{80}$ Dozy, Supplément, t. 2, p. 636: mayyār, muletier qui transporte les marchandises d'un lieu dans un autre, celui qui transporte le vin pour le débiter. 
[Farağ Ğabbās], qui tient en 1492 une maison, en compagnie de «Maestre Yuçaf, cuchillero» $^{81}$, n'est sans doute pas plâtrier, ou staffeur ${ }^{82}$, car le mot de jebes constitue un hapax en castillan, à côté des multiples yeseros musulmans attestés dans la ville. À Tolède également, Maestre Ali el Dabac ['Alī al-Dabbāg̀], qui faisait abandon en 1419, d'une boutique située aux Alatares ${ }^{83}$, n'était probablement pas teinturier, comme l'indiquerait son surnom arabe. Il n'est pas vraisemblable que le scribe chrétien, portugais ou castillan, ait utilisé ces mots, qui ne sont jamais passés dans leur langue, en en comprenant le sens professionnel ${ }^{84}$.

Ainsi, avec les noms de métiers arabes fossilisés en castillan ou en portugais, on entre dans le domaine du laqab, du surnom proprement dit. Si certains d'entre eux, tels les mayyār , ğabbās, ou dabbāg mentionnés se laissent bien comprendre, en leurs origines, d'autres sont plus énigmatiques. Ainsi le nom de Jufez Albargil, qui reçoit en 1440 confirmation d'un privilège ${ }^{85}$, comporte-t-il peut-être à l'origine une nisba géographique ou un nom de métier ${ }^{86}$, devenu un surnom familial, ou laqab.

D'autres surnoms paraissent arabes, sans qu'il soit le plus souvent possible de savoir s'il s'agit d'un surnom personnel, qui impliquerait une pratique courante de la langue, sous sa forme évidemment dialectale, dans la communauté, ou un nom déjà fossilisé, voire familial. Ainsi Ali Xamete, nommé alcaide de la comuna d'Elvas en 1450, sur élection de la communauté8 ${ }^{87}$, paraît-il porter un laqab arabe plutôt qu'un surnom portugais ${ }^{88}$.

Il reste que la grande majorité du second élément, quand il y en a un, du nom des mudéjars, tant lisboètes ou portugais, que tolédans, sont des termes romans, parfois il est vrai directement décalqués de l'arabe. Ainsi, à Tolède, «el Zarco» ou «el Sarco», avec le diminutif «Sarquillo», est un calque de l'arabe «al-azraq» (celui qui a les yeux bleus). Mais comme le mot existe comme emprunt du castillan à l'arabe, on le considérera plutôt comme tel, et non comme arabe, et il paraît déjà un nom familial. Cependant, les mudéjars qui le portent paraissent appartenir à des milieux sociaux

${ }^{81}$ ASC, leg. 44/6.

${ }^{82}$ Dozy, Supplément, t. 1, p. 171b: ğabbās, plâtrier, qui fait ou vend le plâtre.

${ }^{83} \mathrm{OF}$, capilla de San Blas, $\mathrm{f}^{\circ} 62$.

${ }^{84}$ Barros, Tempos e Espaços, p. 271, 297, montre que les professions attribuées en portugais ne correspondent pas au sens des mots en arabe, et indique d'autres noms de ce type, tels que al-mallāh (le saunier), al-haffäf (?), al-gannām (le berger). Nous en excluons al-baytāar (le vétérinaire ou maréchalferrand), passé en langue romane (esp. albeitar, port. alveitar).

${ }^{85}$ Barros, A Comuna, p. 108, et n. 45.

${ }^{86}$ On peut imaginer le dérivé d'un nom de lieu en Burğ, ou en Burgo, ou bien un nom de métier correspondant à burğ al-hamām, colombier (cf. Dozy, Suppl ément, t. 1, p. 65: burğl̄, colombe que l'on nourrit dans un colombier). Des dérivés romans en -il de nisba sont par ailleurs, attestés tels «Martín Granadixil» à Tolède en 1155 (Francisco J. Hernández, Los Cartularios de Toledo. Catálogo documental, Madrid, Fundación Ramón Areces, 1985, n 107).

${ }^{87}$ ANTT, Chancelaria de D. Afonso V, livro 34, fo 38, selon lecture de F. Barros.

${ }^{88}$ Xamete paraît représenter l'arabe šamìt, plutôt que le portugais xamate (échec-et-mat). cf. šamița, grisonner (H. Wehr, A Dictionary of Modern Written Arabic; Kazimirski, Dictionnaire Arabe-Français) et šamìt, mêlé, mélangé (Kazimirski), la forme classique pour "qui a les cheveux grisonnants" étant ašmat. 
différents par leurs professions, et, sans lien apparent entre eux, à des familles distinctes ${ }^{89}$.

Le cas est différent, s'agissant d'un mot d'arabe hispanique qui n'est jamais passé dans la langue espagnole ou portugaise, même si son origine lointaine est romane. Entre 1407 et 1411 apparaissent deux maçons porteurs du surnom «Caracacho»: le premier est désigné une fois comme «Maestre Hamete, aluanne», fils de «Maestre Aly Caracacho», et une seconde fois comme " Maestre Hamete Caracacho, aluanne», et le second, appelé «Maestre Abdalla Caracacho, aluannil» est appelé à expertiser une maison ${ }^{90}$. Il semble bien que «Caracacho» représente l'arabe hispanique qaraqağ, signifiant le concombre ${ }^{91}$.

Un nom bien arabe à Tolède est celui des Almahuaque. En 1344, «don Hamete Almahuac» reçoit une procuration d'une noble dame de la ville ${ }^{92}$. Au siècle suivant, trois au moins des porteurs de ce nom sont d'un notable niveau social, l'un changeur, l'autre intendant du principal magnat de la ville, le troisième chargé de répartir les impôts des musulmans du royaume. En 1438, «don Abdallah Mahuaque, moro, canbiador» est mentionné dans le testament du seigneur de Pinto et Higares, à propos d'une maison jouxtant la sienne ${ }^{93}$. Dès 1422, «Maestre Abdalla Maguac» était présent dans le secteur, en compagnie d'autres musulmans, lorsque le même Fernand Álvarez de Toledo acquérait la maison ${ }^{94}$. En 1433, «don Abrahem Almuhaque» est contador de Pero López de Ayala ${ }^{95}$. Désigné comme «don Abrahem Almahuaque, fijo de Hamete Almahuaque, mayordomo de Pero Lopes de Ayala», il obtient une exemption viagère de 300 maravedís sur l'impôt à payer par la communauté musulmane de

${ }^{89}$ Une maison de «don Hamete el Sarco, yerno de Mohres», en 1343 (AHN, Clero, carp. 3116/13). Une maison ayant appartenu à «don Abdalla el Sarco», en 1368 (AHN, Clero, carp. 3117/4). «don Yuçaf, ffijo de don Abdalla el Zarco, moro morador en Toledo», vend, en 1370 (AHN, Clero, carp. 3117/5), le même appelé «don Yuçaff, espeçiero, ffiio de don Abdalla el Zarco», tuteur des enfants de son frère Mohgrez, en 1379 (AHN, Clero, carp. 3118/16), le même encore, et sa femme, doña Xamçi, fille de l'alfaqui don Abrahem Xarafi, vendent en 1384 (AHN, Clero, carp. 3074/2). En 1400-1408, «Yaya, moro, espeçiero, morador en Toledo» ou «Yahia, espeçiero, moro, sobrino de don Yuçaf Sarco», tient une boutique du Chapitre cathédral, «en los Alatares» (OF 1071, fo $79 \mathrm{r}^{\circ}$; OF 935, fo $31 \mathrm{v}^{\circ}$; OF 936, $\mathrm{f}^{\circ}$ $\left.99 \mathrm{v}^{\circ}\right)$. En 1404, les religieuses de Santo Domingo el Real donnent à cens à «Maestre Abdalla, alfahar», fils de «Hamete el Sarquillo», et à sa femme, doña Haxa, «moros moradores en Toledo», une maison située à l'Arrabal «a los alfahares» (AHN, Clero, carp. 3078/12). La même année, «Yahya, alfarero», et «Mahomat Zarco, alfarero», «moros moradores en Toledo», prennent du Chapitre cathédral, le «Corral de los alfahares, que dicen el Corral de Santa María», dans l'Arrabal de Tolède (OF 1072, $\left.\mathrm{f}^{\circ} 21 \mathrm{v}^{\circ}\right)$. En 1450, le corral de «Maestre Abdalla Sarquillo», comme confront, à l'Arrabal (OF 1090, $\mathrm{f}^{\circ} 157 \mathrm{r}^{\circ}$ ). En 1463, «Maestre Abdalla Sarquillo, çapatero, moro, morador en Toledo», caution de «Maestre Yuçaf Adolasis, alfaharero» (OF 1094, fo $499 \mathrm{v}^{\circ}$ ).

${ }^{90}$ AHN, Clero, carp. 3079/8, 3080/4 et 2990/12.

${ }^{91}$ Dozy, Supplément, t. 2, p. 343, avec référenc à F. J. Simonet, Glosario de voces ibéricas y latinas usadas entre los Mozárabes, et à Schiaparelli, Vocabulista in arabico. Pour les noms de plantes utilisés comme surnoms, cf. Labarta, La onomástica, p. 142-143, où figure un «cogonbro».

${ }^{92}$ ASC, carp. 13/13.

93 Academia de la Historia, Col. Salazar, M-22, f $245 \mathrm{v}^{\circ}$.

${ }^{94}$ AHN, Clero, carp. 3016/3. J.-P. Molénat, Campagnes et Monts de Tolède du XIIe au XVe siècle, Madrid, 1997, p. 346, note 224.

95 ADF leg $279 / 5$. 
Tolède, à partir de l'année 1435, qui reste valable en $1452^{96}$. Vraisemblablement un autre Abrahem Maguaque, fils de Hamete Magueque, habitant de Tolède, est désigné le 6 mars 1492 comme l'un des répartiteurs du servicio e medio servicio des musulmans du royaume. Mais il ne tarde pas à émigrer, avant même l'abolition du statut des mudéjars en février 1502, un successeur lui ayant été donné à une date non précisée $^{97}$. D'autres mudéjars tolédans portent encore le même nom: en 1484, «Abdalla Maguaque», fils de feu «don Mahomad Maguaque», désigné par son père pour lui succéder, s'oblige pour deux boutiques situées dans l'Alcaná, et, un peu plus tard, "Yuçaf Almahuaque» apporte sa caution ${ }^{98}$. Le nom s'interprète sans doute comme almawwāq (le botier), terme professionnel ne s'appliquant plus aux mudéjars tolédans cités. Mais il apparaît déjà pour l'un des rares musulmans présents à Tolède au XIIe siècle ${ }^{99}$, et d'autre part on connaît Muhammad b. Yūsuf b. Abī l-Qāsim al-'Abdarī

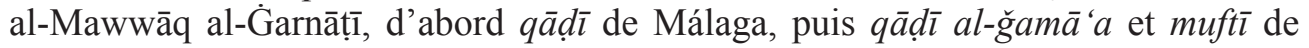
Grenade, au moment de la conquête de la ville, mort quelques mois plus tard, en 897 $\mathrm{H} / 1492$, auteur de diverses œuvres de droit ${ }^{100}$. Nous ignorons cependant toute relation entre le juriste grenadin et ses homonymes, les mudéjares tolédans du XII ${ }^{\mathrm{e}}$ au XV siècle ${ }^{101}$.

Un surnom, d'origine clairement arabe, qui nous reste obscur, est celui de «don Hamete el Muhnar», alcalde de los moros de Tolède, qui prend possession, en janvier 1404, de la moitié du village de Fuensalida, au nom de Pero López de Ayala, alcalde mayor de la ville ${ }^{102}$.

On peut voir les listes de professions, toujours exprimées en langue romane, des mudéjars, portugais et tolédans, données par Filomena Barros ${ }^{103}$ et par nous-même ${ }^{104}$.

Pour les autres types de «surnoms», il en est que l'on pourrait considérer comme de sobriquets, à l'occasion même injurieux ou despréciatifs. À Tolède, on trouve, «Abdalla Correenbalde», fils de «Mahomad Correenbalde» (court-en-vain) possesseur d'une part de moulin sur le Tage, déjà décédé en $1369^{105}$. Au Portugal, en 1461, «Caçome Borracho» (ivrogne), potier, demeurant à Lisbonne («oleiro, morador em

${ }^{96}$ AGS, Mercedes y Privilegios, leg. 1, fo 421 et leg. 2, fo 371.

${ }^{97}$ AGS, Mercedes y Privilegios, leg. 76, $\mathrm{f}^{\circ} 39$.

${ }^{98}$ OF $1285, \mathrm{f}^{\circ} 34 \mathrm{r}^{\circ}$; OF $1287, \mathrm{f}^{\circ} 11 \mathrm{r}^{\circ}$.

${ }^{99}$ En 1167 une maison des héritiers de Muhammad al-Mawwāq, dans le quartier de la cathédrale (MT 898). En 1182 et 1187, la maison d'al-Mawwāq le musulman, dans le même secteur (MT 160, 738)

${ }^{100}$ M. I. Calero Secall, «Referencias a Málaga en el Mi 'yār al-muġrib de al-Wanšarīisì», dans Multaqā al-dirāsāt al-Magribiyya al-Andalusiyya, Tétouan, 1995, p. 3-14, spécialement p. 7, n. 12. L. Seco de Lucena, «La escuela de juristas granadinos en el siglo XV», Miscelanea de Estudios Árabes y Hebraicos 8 (1959), p. 7-28. Fernando [Rodríguez] Mediano, Familias de Fez (ss. XV-XVII), Madrid, CSIC, 1995, p. 198-200.

${ }^{101}$ On peut ajouter que le nom existe encore au Maghreb, comme l'atteste celui de notre collègue et ami Mohammed Meouak.

${ }^{102}$ ADF, leg. 249. Nous avions d'abord lu «don Hamete el Mahnat», encore plus obscur.

${ }^{103}$ Tempos e Espaços, p. 297, dans la colonne des noms en portugais, les noms arabes ayant, comme nous l'avons dit plus haut, et comme l'écrit F. Barros, une autre signification.

104 J.-P. Molénat, «Les mudéjars de Tolède: occupations professionnelles et localisation dans l'espace», art. cit. supra.

${ }^{105}$ CT, V.10.A.1.15. De même se vendait en 1358 une maison ayant appartenu à Mahomad Correenbalde (AHN, Clero, carpeta 3116/18). 
a ... cidade de Lixboa»), bénéficie d'un privilège d'exemption fiscale, accordé par le roi, parce que, dit celui-ci, «il nous sert et doit nous servir dans les œuvres de notre palais de Sintra, en ce qui appartient à son métier» ${ }^{106}$. Par conséquent le «Borracho» paraît pouvoir constituer un nom familial plutôt qu'un sobriquet, qui serait déplacé en la circonstance ${ }^{107}$. De même, dans le cas des Correenbalde, le fait que le père et le fils, aient été pourvus du même surnom, peu commun, laisse penser que plutôt qu'un sobriquet, il s'agissait d'un nom familial, ou plutôt que le sobriquet s'est déjà transformé en nom familial. Un autre nom de ce type au Portugal est celui de Mafamede «Baboso» (baveux, niais) ${ }^{108}$.

Les surnoms, spécialement au Portugal, peuvent être des noms d'animaux (À Lisbonne, «Lobo», loup ${ }^{109}$; «Láparo», lapereau ou jeune lièvre ${ }^{110}$; à Santarém, «Ratinho», petit ras ou souriceau ${ }^{111}$ ). Nous n'en avons pas relevé à Tolède.

Les noms d'origine, en espagnol ou en portugais («de tel endroit», ou un adjectif) indiquent vraisemblablement, sauf exceptions, une provenance plus récente que les nisba/s géographiques arabes, qui signifiraient le souvenir d'une immigration, ou plutôt d'une transplantation plus ancienne, par exemple pour les Xarafi à Tolède.

\section{COMMENT INTERPRÉTER CETTE ONOMASTIQUE?}

La plupart des chercheurs, malgré leur petit nombre ${ }^{112}$, qui se sont intéressés à cette question, y compris Filomena Barros, voient dans l'onomastique des mudéjars un témoignage de leur acculturation au milieu chrétien. L'argument essentiel de Filomena Barros sur ce point réside dans ce qu'elle considère comme l'adoption de la structure le plus souvent binaire du nom conforme au modèle chrétien ${ }^{113}$.

${ }^{106}$ Barros, A Comuna, p. 143, et note 47, s'interrogeant sur le point de savoir s'il y a un rapport avec la technique des azulejos, et spécialement ceux du palais de Sintra.

${ }^{107}$ Une autre signification du terme de «borracho» en portugais est celle de jeune pigeon, ce qui le placerait dans la catégorie des noms d'animaux.

${ }^{108}$ En conflit sur les attributions d'escrivão à Loulé en 1488 (Barros, A Comuna, p 46, n. 59).

${ }^{109}$ «Azmede Lobo», tapissier (tapeteiro) de Lisbonne, reconnu comme privilégié par João II, sans date spécifié (Barros, A Comuna, p. 147, n. 56). Le nom Lobo est également porté par des nobles portugais chrétiens.

${ }^{110}$ Azmede et Caçome, tous deux fils de Mafamede Láparo, tapeteiros, privilégiés sous D. Duarte. voient leur charte confirmée en 1440 par le régent D. Pedro (Barros, A Comuna, p. 147, 149). Mafamede Láparo, dernier capelão dos mouros de Lisbonne, est encore présent en 1506 (Barros, A Comuna, p. 246, n. 89)

${ }^{111}$ Mafamede Ratinho, 1463-1468 (M. F. Lopes de Barros, «O conflito entre o mosteiro de Chelas e Mafamede Ratinho, mouro forro de Santarém (1463-1465)», Revista de Ciências Históricas da Universidade Portucalense Infante D. Henrique (1988), p. 239-244).

${ }^{112}$ Miguel Ángel Ladero Quesada, pionnier des travaux modernes sur les mudéjars, écrit que «le régime des noms familiaux (apellidos) mudéjars suit souvent celui général de la population et la construction onomastique arabe s'est perdue» (nous traduisons) (Los mudéjares de Castilla y otros estudios de historia medieval andaluza, Grenade, 1989, p.73)

${ }^{113}$ Ainsi (Tempos e Espaços, p. 277): «l'évolution culturelle du groupe qui, au XVe siècle, paraît assumer les modèles anthoponymiques caractéristiques du reste de la population du royaume, en ce qui concerne la structure binaire de ceux-ci» (nous traduisons). 
Il est vrai que les noms des mudéjars, tels qu'ils apparaissent dans les documents, sont le plus souvent formés de deux éléments: ce que nous nommons le «nom personnel», semblable au ism 'alam arabe et comparable au prénom chrétien, et un autre élément, de nature d'ailleurs très variable, comme nous l'avons montré précédemment.

Mais plusieurs observations doivent être faites, avant d'aller plus loin. La première est que l'immense majorité de nos documents sont le fait de scribes, ou de notaires chrétiens, certainement peu informés de la complexité du nom arabe, qui appliquent nécessairement, quand ils écrivent, leurs propres schémas, linguistiques ou culturels en général. On peut penser qu'ils accomodent à leurs usages une pratique peut-être différente des hommes et des femmes dont ils parlent, mais qui ne parlent que rarement effectivement à la première personne. Ceci ne prouve encore rien, mais constitue seulement une mise en garde, une incitation à nous montrer plus attentifs, au delà de la première apparence.

La seconde observation est qu'il n'est pas vrai que le modèle anthroponymique des chrétiens hispaniques des XIVe et XVe siècles, soit, de manière générale binaire. On est souvent en présence d'un modèle ternaire, formé d'un prénom, d'un patronymique et d'un nom d'origine (ou surnom différent), en Castille, comme au Portugal $^{114}$. Seul le premier élément, le prénom, est toujours présent, alors que le deuxième (patronymique) et le troisième (nom d'origine-surnom) peuvent soit alterner soit être simultanément présents. Il faut rappeler que le patronymique, spécificité ibérique ${ }^{115}$, est en principe le nom du père suivi de la désinence -ez (-es en portugais), mais que dans la pratique il a tendance à se maintenir de générations en générations, au moins en Castille, car au Portugal jusqu'à la fin du XVe siècle il continue de correspondre effectivement au nom du père. Ce patronymique en -ez/-es, très présent chez les chrétiens portugais comme castillans, n'existe jamais chez les mudéjars de l'un ou l'autre royaume, pas plus, probablement, que chez ceux de la Couronne d'Aragon ${ }^{116}$. On a vu que chez les mudéjars, tant portugais que tolédans, la filiation s'exprime d'autres manières, plus proches du nasab arabe (soit par Iben/Aben/Ben, soit par hijo de/ filho de, soit par la simple juxtaposition du nom du père). Si la signification de ces formations est la même que celle du patronymique en son origine, elles en sont néanmoins distinctes, tout se passant comme si le patronymique était l'apanage exclusif du chrétien.

Les rares documents bilingues que l'on possède, laissent apparaitre une pratique différente pour le même individu selon la langue utilisée, à l'exemple des deux Xarafí, le père et le fils, appelés respectivement Mahomad et Hamete, signant en 1347 à Tolède, une traduction réalisée par eux: Mahomad el Xarafi et Hamete el Xarafi en castillan, mais aussi en arabe: «Moi Muḥammad b. 'Alī al-Muḥnafì al-Šarafī» et

${ }^{114}$ Pour le système anthroponymique chrétien au Portugal, que nous avons moins fréquenté que celui de Castille, et particulièrement de Tolède, nous nous référons aux travaux d'Iria Gonçalves: «Amostra de antroponímia alentejana do século XV», Do Tempo e da História 4 (1971), p. 173-212, reproduit dans Imagens do Mundo Medieval, Lisbonne, 1988, p. 69-104, et «Antroponímia das terras alcobacenses nos fins da Idade Média», Do Tempo e da História 5 (1972), p. 159-200, reproduit dans Imagens do Mundo Medieval, p. 105-142.

${ }^{115}$ Patronímico, en espagnol comme en portugais, est différent du patronyme français, qui n'est qu'un autre mot pour le nom de famille.

${ }^{116}$ Labarta, La onomástica, p. 131, relève un certain nombre de cas, peu nombreux, de patronymiques en -ez/-es/-is. Mais il s'agit de morisques, officiellement chrétiens. 
«Moi Ḥamad b. Muhammad b. 'Alī al-Muhnafī al-Šarafì̀, avec ism 'alam, nasab (noms du père et du grand-père), et une double nisba, et où il ne manquerait qu'une kunya pour que l'on soit en présence d'un nom arabe complet ${ }^{117}$.

En Castille encore, à une date imprécise de la première moitié du $\mathrm{XV}^{\mathrm{e}}$ siècle, l'auteur de l'un des rares documents conservés de la pratique des alcaldes mayores de moros du royaume, est désigné dans le corps du texte castillan comme: «don Mahomad, alcalle mayor por nuestro sennor el rey, de todas las aljamas de los sus regnos e sennorios», mais signe en arabe comme «Muhammad b. Yüsuf al-Qaysī ${ }^{118}{ }^{18}$. Il a toutes chances de s'identifier avec «Don Mahomad de Toledo, moro, alcall mayor de las aljamas de los moros de Castilla», qui apparaît en 1408, au nom de ses enfants, dans la liquidation d'un procès portant sur la propriété des quatre-vingt quatre boutiques des Alatares de Tolède ${ }^{119}$. En 1424, est vendue une maison qui lui avait appartenu auparavant: «fueron de don Mahomad alcall» ${ }^{120}$. En 1458, on parle à Tolède d'une maison appartenant aux héritiers de feu «don Mahomad Alcayçi, alcalde mayor que fue de las aljamas de los moros de Castilla $\rangle^{121}$. La nisba tribale n'apparait que dans la signature arabe, ou, en castillan, après le décès de l'intéressé, la filiation (nasab) seulement dans la signature. Le nom peut-être réduit au seul élément personnel (ism 'alam), éventuellement précisé par la fonction, ou par une désignation géographique, qui ne peut d'autant moins être considérée comme un nom familial (esp. apellido), que l'extraodinaire abondance du «de Toledo» à Tolède même lui donne évidemment une signification différente ${ }^{122}$. À partir des diverses manières de le désigner en castillan, on pourrait reconstituer un nom arabe presque complet, avec ism 'alam, nasab, laqab, nisba tribale et géographique: Muhammad b. Yūsuf al-Qaysī al-Tulayțlì al$q \bar{a} d \bar{l}$, auquel il ne manquerait que la kunya. Mais la pratique de la kunya apparaît dans les documents arabes récemment publiés d'une confrérie islamique de Tolède au début du XV siècle, où l'on trouve le qā ḍī Abū 'Abd Allāh Muhammad al-Qaysī ou le faqīh Abū 1-'Abbās Aḥmad al-Šarafì, entre autres exemples ${ }^{123}$, et où la présence

${ }^{117}$ F. Fita, «Marjadraque según el fuero de Toledo», Boletín de la Real Academia de la Historia 7 (1885), doc. 5, p. 376. J.-P. Molénat, «Une famille de l'élite mudéjare de la Couronne de Castille: les Xarafí de Tolède et Alcalá de Henares», Mélanges Louis Cardaillac. Études réunies et préfacées par Abdeljelil Temimi, Zaghouan (Tunisie), 1995, t. 2, p. 765-772.

${ }^{118}$ E. Sáez, Colección diplomática de Sepúlveda 1, Ségovie, 1956, p. 534-538.

${ }^{119}$ CT, E.6.A.2.2. Notice dans Ramón Gonzálvez Ruiz, Hombres y libros de Toledo, Madrid, Fundación Ramón Areces, 1997, p. 61, note 76.

${ }^{120}$ AHN, Clero, carp. 3084/6.

${ }^{121}$ AHN, Clero, carp. 2091/5.

122 Sur le nom «de Toledo» chez les chrétiens à Tolède, et son parfum aristocratique, servant souvent, au XVe siècle, à masquer une ascendance conversa, cf. J.-P. Molénat, «L'onomastique tolédane». Ce n'est évidemment pas encore le cas pour Mahomad de Toledo, pour qui l'emploi du nom d'origine locale est proche de celui de la nisba géographique en arabe, sans s'identifier exactement à celle-ci.

${ }^{123}$ Ana Echevarría et Rafael Mayor, «Las actas de reunión de una cofradía islámica de Toledo. Una fuente árabe para el estudio de los mudéjares castellanos. Años 1402 a 1414», Boletín de la Real Academia de la Historia 207/2 (2010), p. 257-293, spécifiquement p. 263, 265 (texte) et 279, 281 (traduction). On ne saurait trop insister sur l'importance de ce document quant au maintien non seulement d'une onomastique arabe, mais aussi d'une pratique acceptable de la langue, au cœur de la Castille, dans la première moitié du XVe siècle, confirmant ce que nous avions avancé dans des travaux antérieurs, basés exclusivement sur des documents en langue castillane. Le présent article a été rédigé 
conjointe de la kunya et du ism 'alam montre que la première ne s'était pas encore transformée en nom propre et conservait sa fonction de «voile du nom», selon l'heureuse expression de Jacqueline Sublet ${ }^{124}$.

De même au Portugal, le notaire de la communauté musulmane de Lisbonne, à la fin du XIVe siècle ou au début du XVe, après avoir signé en arabe de son nom presque complet Yūsuf b. Ibrāhīm b. Yüsuf al-Lahmmī, avec ism 'alam, nasab et nisba tribale, auquel ne manque là aussi que la kunya, contresigne-t-il en caractères latins seulement $J u f f i z$, selon la forme passée en portugais de son nom personnel ${ }^{125}$. Au Portugal encore, à Santarém, en 1478, le même homme, désigné dans le corps du document comme Brafome Çaide Izbrela [Ibrāhīm b. Sa'īd b. Ḥasab Allāh], et ailleurs comme «Brafeme, neto de Mestre Azbala», et «Brafome, filho de Çaide, neto de Mestre Azbolla», signe un contrat seulement comme «Brafeme» ${ }^{126}$. Dans ce cas, les désignations du texte plus longues que celle de la signature laissent seulement apparaitre quelque chose du système arabe, un nasab qui n'est pas réduit à une seule génération.

Dans les deux premiers cas, seul subsiste, dans la version castillane ou portugaise du nom, le nom personnel, dans une transcription correspondant à sa forme passée dans la langue romane à travers la réalisation arabe dialectale, tandis qu'est tombé tout ce qui fait la singularité du système anthroponymique arabe: nasab, nisba et bien sûr kunya. Cet accourcissement de la désignation n'est pas, dans ces deux exemples au moins, le fait d'un scribe chrétien, bien que ce puisse l'être dans d'autres cas ${ }^{127}$, mais celui du mudéjar en question lui-même, s'agissant d'une signature. On peut l'interpréter de diverses façons. Tout d'abord, dire que nous-mêmes avons coutume, par simple commodité, de signer d'un seul nom, généralement le nom de famille, ou le prénom dans des lettres plus familières. Filomena Barros voit là «une contamination culturelle des musulmans portugais, à travers l'adoption des paramètres anthroponymiques de la majorité»» ${ }^{128}$. Nous dirions plutôt que la réduction du nom à un seul terme signifie pour le mudéjar, en même temps que la renonciation apparente à la complexité du nom arabe, impossible à mettre en forme dans le contexte d'un document en langue et graphie portugaise ou castillane, le refus de l'adoption des «paramètres anthroponymiques de la majorité», c'est-à-dire ici, d'un nom personnel suivi d'un nom familial.

en 2009, avant que nous ne puissions avoir connaissance de cette nouvelle donnée, et sa publication retardée pour des raisons indépendantes de notre volonté. Nous remercions vivement Miguel Angel Ladero Quesada de l'avoir accepté ici.

${ }^{124}$ Le voile du nom. Essai sur le nom propre arabe, Paris, PUF, 1991.

${ }^{125}$ Barros, Tempos e Espaços, p. 253, 361.

${ }^{126}$ Barros, Tempos e Espaços, p. 266, 277, et figure 5.5, p. 256)

${ }^{127}$ C'est probablement le même Jufez, notaire (tabelião) de la comuna de Lisbonne, en conflit en 1402 avec le procureur du roi, pour avoir occupé durant des années la charge, sans payer les droits (la pensão) correspondants, et obligé désormais de les acquitter (Barros, A comuna, p. 126, n. 18, et p. 97, n. 21). Ici le raccourcissement du nom à un seul terme est le fait du notaire de la chancellerie royale, qui ignore, ou veut ignorer, les complexités du nom arabe. Peut-être le fils du même, nommé également Jufez, mouro de Lisbonne, fils du tabelião, bénéficie d'une exemption en 1461 (Barros, A comuna, p. 108, n. 44, et p. 120, n. 74).

${ }^{128}$ Nous traduisons (Barros, Tempos e Espaços, p. 277). 
Pour le scribe chrétien, y compris le notaire de la chancellerie royale, la réduction, si fréquente, du nom du mudéjar, à un seul terme, accompagné à l'occasion d'un sobriquet, ou d'une désignation professionnelle, pour parvenir quand même à identifier l'intéressé, signifie le refus, ou l'ignorance, des complexités du nom arabe. On peut penser d'ailleurs que les mudéjars du commun ne devaient pas disposer du stock de richesses onomastiques réservées à leur élite, mais, comme on a pu le voir, la réduction onomastique pouvait aussi atteindre les membres de celle-ci.

Pourtant ces richesses onomastiques réapparaissent à l'occasion, et tout d'abord dans le documents bilingues déjà mentionnés, ou à travers les diverses désignations successives du même personnage, comme des membra disjecta d'un nom arabe presque, ou vraiment, complet, comme c'est le cas pour Mahomad de Toledo, alias Abū 'Abd Allāh Muhammad b. Yūsuf al-Qaysī. Mais elles surgissent également dans les épitaphes, telles l'inscription funéraire déjà citée d'Abū l-Walīd Ismā'il b. Abī 'Abd Allāh al-Anșārī, personnage sur lequel nous ne savons rien d'autre que la date de son décès (1368) et le lieu de la découverte de cette inscription, Moura. Faut-il y voir, avec l'emploi de l'écriture arabe et de la datation hégirienne, l'expression d'un «monde des morts», fidèle aux rites islamiques, opposé au «monde des vivants», acculturé («mudéjarisé» selon l'expression de Filomena Barros ${ }^{129}$ ) ? Nous serions au contraire tenté de rapprocher ces épitaphes des signatures, également en graphie arabe et supports d'une onomastique proche de celle classique en arabe et de celle des épitaphes. Epitaphes et signatures sont presque ${ }^{130}$ les seuls endroits qui nous soient parvenus où les mudéjars aient pu s'exprimer par eux-mêmes, sans le filtre imposé par la société chrétienne environnante et dominante. Les musulmans de Castille ou du Portugal lorsqu'ils s'exprimaient devant les notaires et scribes chrétiens devaient bien, pour se faire entendre, employer la langue des dominants, avec tout ce qu'elle véhiculait. De là à dire qu'ils avaient non seulement assimilé la langue de ceux-ci, mais encore intériorisé leurs valeurs, en un mot qu'ils s'étaient acculturés, il y a un pas, qu'il nous paraît aventuré de franchir trop vite.

Il serait certainement absurde de prétendre que les mudéjars, après plusieurs siècles, au moins deux et demi, sinon plus, de vie comme une minorité enclavée au milieu des chrétiens hispaniques très largement majoritaires et dominant, n'aient pas connu une certaine forme d'acculturation, les rendant plus susceptibles d'accepter le baptême, respectivement en 1497 et 1502, pour ce qui concerne le Portugal et la Castille $^{131}$. Nous avons seulement voulu montrer, à travers l'onomastique, généralement acceptée comme la preuve de cette acculturation, l'existence d'une résistance à cette acculturation, d'une fidélité aux paramètres arabes classiques, cachée le plus souvent derrière l'apparence d'une conformité aux modèles chrétiens hispaniques dominant.

${ }^{129}$ Barros, Tempos e Espaços, p. 236.

${ }^{130}$ La réserve est mise là pour tenir compte des actes de la confrérie islamique de Tolède, publié par A. Echevarría et R. Mayor, dans l'article cité plus haut.

${ }^{131}$ J.-P. Molénat, «Des "vieux mudéjars " aux morisques de Castille (fin XVe-début XVIe siècle)», communication au congrès Los Moriscos. Historia de una minoría, Grenade, 13-16 mai 2009, à paraître, où nous montrons la résistance différente à la conversion, et à ce qu'elle impliquait, suivant les dimensions des communautés concernées, les plus grosses, vraisemblablement les moins acculturées, offrant la plus forte résistance. Le cas emblématique est fourni par Hornachos, la plus forte aljama de Castille, et la seule localité intégralement peuplée de mudéjars. 
Nous concéderons volontiers que les témoignages de cette résistance sont les plus apparents au XIV siècle et au début du $\mathrm{XV}^{\mathrm{e}}$, et que la conformité aux modèles des dominants se fait plus générale à la veille des édits de conversion-expulsion de 1497 et 1502. Elle n'est cependant pas totale, des noms bien arabes subsistant, employés à la manière des noms familiaux (apellidos) chrétiens. 